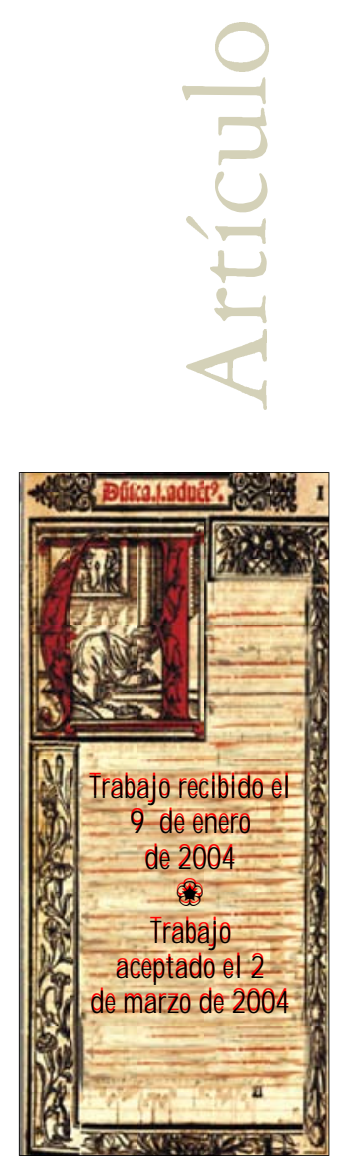

\title{
Factores socio-culturales para una historia de la archivística*
}

\author{
Agustín Vivas Moreno \\ Facultad de Documentación, Universidad de Extremadura, Alcazaba, 06071 \\ Badajoz, España, Tfno. Código internacional de España \\ $+924236342-$ Ext. 6432. \\ E-mail: avivas@alcazaba.unex.es
}

\section{RESUMEN}

El presente artículo tiene como objetivo analizar los factores socio-culturales que han contribuido de forma decidida al desarrollo histórico de la disciplina archivística. Entendemos por factor socioaltural las estructuras que permanecen constantes durante un largo periodo y que pretenden dar como resultado una Histaia dela Ardivística delarga duracoón esto es, de elementos estables. Así, concebimos que dichos factores socio-culturales son: la altura exita, la prádica elesástica, la salvaguardaygarantíajuńdica, la burcaradaylavisióndl archivo comoinstrumentopdítica la memniahistóncay la funcióninfomativa. En el desarrollo metodológico del artículo exponemos cómo cada uno de los dichos factores ha articulado en su devenir histórico la configuración de la archivística. De todo ello, extraemos dos resultados principales: en primer lugar, inferimos que dichos factores son básicos para la comprensión de la histaiaaltural delaardhiv́stica, concepto innovador; y en segundo lugar, comprobamos el carácter interdisciplinar de dicha disciplina. En definitiva, y como conclusión, demostramos que dichos factores socio-culturales han contribuido conjuntamente al despliegue de la archivística, ya sea mediante sus pretensiones de conservación e intemporalidad, como elementos propiciadores de la complejidad administrativa, como favorecedores de la utilización del documento como instrumento cultural y político, o como agentes que colaboran directamente en la integración del archivo en las funciones informativas.

Palabras Clave: Factores socio-culturales, Historia de la archivística, Historia cultural.

\section{SOCIO-CULTURAL FACTORS FOR A HISTORY OF ARCHIVES AgUSTÍN VIVAS-MORENO}

\begin{abstract}
The socio-cultural factors that have had important implications for the historical development of archival science are analyzed. We take as socio-cultural those structures which remain constant during a long period of time and which give rise to a History of archival science; that is the stable elements. We conceive that such cultural factors are: wittenalture edesiastical practice, junidical safeguard and wanranty, bureauragy and its vision of archives as a political instrument, historical memoryandtheinfomativefunction We state the way in which each one of these factors has articulated by way of its historical
\end{abstract}

\footnotetext{
* El presente trabajo se ha realizado en el marco del proyecto de investigación concedido por el Ministerio deCiencia y Tecnología de España, con referencia BMA2000-1336.
} 
occurrence, the configuration of archival science. From this we draw two main results: first, we infer that such factors are basic for the understanding of the altural histary of ardival scienes an innovative concept; and second, we confirm the interdisciplinary character of the discipline. In conclusion we demonstrate that the said socio-cultural factors have contributed to the development of archival science, either through its pretensions of conservation and untemporality, or as propitiating elements in the administrative complexity, or as positive elements in utilization of the document as a political and cultural instrument, or as agents which directly contribute to the integration of archives with respect to their information function.

Keywords: Socio-Cultural Factor, History of Archives, Cultural History.

C uando se procede a explicar, no sólo a describir, la configuración científico-técnica de los archivos y de la archivística como disciplina, cualquier análisis, incluso los más someros, nos conducen hacia un complejo entramadodeinteraccionessociales yalturalesque actúan no sólo como marcos o contextos del panorama archivístico en cada época histórica, sino más aún como factores condicionantes de la forma en que se articularon los archivos y se concibió el trabajo en ellos de los archiveros.

Es sabido cómo los archivos tuvieron, desde sus mismos orígenes, una funciónutilitania de servicio a las entidades o personas en el acopio y conservación de la información, y precisamente por ser heramientasdetrabajo, ya fuese político, económico, religioso o de otro tipo, determinados procesos socioculturales de carácter macroestructural han estado presentes desde que los primeros oficiales sumerios decidieron emplear tiempo y dinero en conservar miles de tablillas de terracota archivadas, hasta los tiempos actuales del ciberespacio y la información en soporte digital. Sin embargo, los procesos históricos están siempre constreñidos espacial y temporalmente, surgen en un determinado lugar y fecha, y son activos en ciertos ámbitos geográfico-cronológicos, mostrándose inactivos en otros y perdiendo influencia de la mano del devenirhistórico.

Por este motivo, los factores que vamos a analizar no tienen carácter de conceptos abstractos, susceptibles de ser aplicados en cualquier lugar y en cualquier época histórica. Antes bien, responden a las experiencias seguidas básicamente en el mundoocidental y, durante algunas épocas, en su entorno geográfico mediterráneo. Paralelamente, y como veremos ahora en detalle, determinados factores que jugaron un papel de capital importancia durante milenios -las prácticas eclesiásticas, por ejemplo-perdieron preponderancia desde los albores de la modernidad; y otros, como la irrupción de las nuevas tecnologías de la información, por ejemplo, son desde luego novedads históricas - en el supuesto de que, con rigor, este concepto pueda ser empleado en Historia.

Los factores a que nos referimos son también procesosdeextradrinaniamagnitud, tanto por su permanencia en el tiempo por encima de periodos históricos y culturas 
diferentes, que introducirán en ellos notorias modificaciones, como por las implicaciones que presentan, en extremo sutiles, con cuestiones económicas, jurídicas, políticas... con todos los ámbitos de la vida social, en suma. Por estos motivos, más que explicarlos, lo cual requeriría de ambiciosos estudios monográficos, lo que vamos a hacer es categorizarlos y, en la medida de lo posible, acotar espacial y temporalmente su aportación concreta a la configuración delos archivos y de la archivística.

Hay que advertir también que, aunque nosotros los expliquemos individualizadamente, ésta es básicamente una imposición didáctica, si bien en la realidad histórica estos factores no actúan de forma autónoma, sino interrelacionados entre sí.

\section{LA CULTURA ESCRITA}

De todas las vinculaciones que podemos establecer entre los archivos y su entorno social y cultural, la que los une con lo que ha dado en llamarse altura saitaes, sin duda, la más evidente, hasta el punto de que bien podría considerarse una precondión para la existencia de archivos, al menos tal y como concebimos éstos en el ámbito occidental. Ha de tomarse en consideración el hecho, probado sin ningún género de dudas por los estudios actuales de antropología y etnografía, que la gran mayoría de las civilizaciones y pueblos que han habitado el planeta no han necesitado ni del documento escrito, ni mucho menos del archivo, para conservar y recuperar con garantías de fidelidad tanto su memoria histórica como los contenidosailturalespropios. ${ }^{1}$ En estos entornos culturales la información se concreta en palabras y rituales y se

1 El tema de los orígenes y evolución de la altura @xitaha generado una ingente bibliografía desde los más diversos enfoques: la Paleografía, la Historia Social, la Semiología, la Antropología, etcétera. Pueden destacarse las siguientes obras:

- Cardona, G. Charta Dal pepiroal computer. Milano, 1988.

- Chartier, R. El mundocomorepresentación Estudios sobrehistaria altural. Barcelona: Gedisa, 1992.

- Darnton, R. Gensdelettres, gensdulive Paris, 1992; Gaur, A. Histariadelaescritura. Madrid, 1989.

- Gelb, I.J. Histaia dela escitura. Barcelona, 1976.

- Gimeno Blay, F.M. y Trenchs Odena, J. "Escritura: palabra e imagen (Reflexiones sobre la cultura escrita reproducida)". A nalesdelaUniversidaddeAlicante HistariaMedieval. 1986, 4-5, pp. 359-378

- Harris, M. Antropdoǵa altural. Madrid, 1990, pp. 81-114; Higounet, Ch. L'éviture París, 1976. - Goody, J. Lalógicadela@xituraylacrganizadóndelasoiedad, Madrid, 1990; Lorenzo Cadarso, P.L.

“La escritura y los procesos sociales". Puatasa la Letura, 1998, 5, pp. 34-38.

- Marichal, R. "La escritura latina y la civilización occidental del siglo I al siglo XVI", en Laescituray la psicolóa delos pudblos, México, 1992, pp. 205-254.

- Martin, H.J. Histaree pawcirs del'énit. París, 1988; Mosterin, J. Tẹna dela escritura. Barcelona, 1993.

- Parkes, M.B. Sarbes, Saiptsandredes Londres, 1991; Petrucci, A. "La scrittura tra ideologia e rappresentazione”, en Storia ddléArteItaliana. 1980, IX, pp. 1-123.

- Idem La scrittura. Idedogia erappresentazione, Torino, 1986; Proust, M., Sdarela lectura. Valencia, 1989.

- Riesco Terrero, A. "Importancia de los elementos estructurales y ritmos vitales en la transformación y diversidad de escrituras antiguas, medievales y modernas (ss. VI a.C.-XVIII d.C.)", en LaEs paña Medieal. III. Estudiosen memoria del Prof. S. deMoxó Madrid, 1982, pp. 353-368.

- Ruiz García, E. Hadia una semidóáa dela @oitura, Madrid, 1992. 


\section{0}

conserva en la memoria, generándose toda una estructura socio-profesional que garantiza la correcta custodia y transmisión de los contenidos culturales: los ancianos, los hechiceros, los sacerdotes, etcétera, cuya palabra, refrendada por la memoria, verifica el contenido cultural transmitido. ${ }^{2}$

El hecho de que en determinados lugares y en el marco de procesos históricos concretos se inventara la escritura supuso la entrada en escena de nuevos agentes culturales y nuevas formas de transmisión de la información. ${ }^{3}$ Los archivos surgen, por lo que sabemos a través de las excavaciones arqueológicas de Próximo Oriente, de forma casi paralela a la escritura, pero no automática, ni mucho menos configurándoselos archivos de un modo equiparable al actual. ${ }^{4}$

En sus orígenes, la escritura está constreñida social y funcionalmente. Son sólo determinados grupos cerrados de sacerdotes y escribas públicos quienes la conocen, y no siempre era necesario un depósito que ejerciera de archivo, dado que también podían servir para ese fin, por ejemplo, la pared de un templo en Egipto o una estela funeraria en Sumer. ${ }^{5}$ La vinculación del origen de la escritura con rituales eclesiásticos, especialmente con el culto a los dioses y con las prácticas funerarias, se evidencia en el hecho de que la mayor parte de los monumentos escritos que han llegado a nosotros tienen este carácter.

2 Vid - Cardona, G.R. "Sull’Etnografia della scrittura”, en Scittura eCiviltà. 1977, 1, pp. 211-218.

- Idam Antropdoǵa dela escitura, Barcelona, 1995.

- Idam Loslenguajes dd saber, Barcelona, 1994.

- Diamond, A.S. Histariayońgenes de lengraje Madrid, 1974.

- Goody, J. La damesticación de pensamientosalvaje Madrid, 1990.

- Havelock, E.A. Cultura araleeđiviltà ddla scritura. Da Omeoa Platone Bari, 1973.

- Jensen, H. Sign, Symbd and Saipt. Londres, 1970.

- Metraux, A. "Los primitivos, señales, símbolos, pictogramas y protoescritura", en La@xiturayla psicolóa delos puedlos México, 1992, pp. 1-22.

- Poca, A. La escritura. Teenáaytémica dela transmisión Barcelona, 1991.

3 Vid

- Jean, G. L'éniture memiredeshommes París, 1987.

- Rossi, P. (Ed.). Lamemniadd sapere Fomedi conservazioneestrutturearganizzativedall'antidhitàa ogj. Roma, 1988.

4 Vid

- Cohen, M. đal., La escriturayla psicdoǵa delos pudblos México, 1963.

- idem L'éniture, la alturee les hommes París, 1953.

- Curto, S. La sorittura ndla staria dell'uoma Milán, 1989.

5 Vid

- Escolar, H. Histaria soial di libra La tablea anefome Madrid, 1974.

- Labat, R. "La escritura cuneiforme y la civilización mesopotámica", en La@cituraylapsicoloǵade lospuddos México, 1992, pp. 69-99. 
La evolución de la escritura, simplificándose y haciéndose más funcional -ideográfica, silábica, alfabética-propiciará su extensión social: los oficiales públicos, los mercaderes y todo aquél que precisase llevar un registro sistemático de su trabajo fueron los colectivos sociales que empezaron a emplearla desde fechas muy tempranas. ${ }^{6}$ Con ellos, la producción documental comenzó a ser significativa y se hicieron necesarios los primeros depósitos de documentos escritos, que son, como decimos, los que encontramos en las excavaciones de Próximo Oriente. ${ }^{7}$ En un proceso lento, la escritura se extendió por las élites sociales del mundo griego ${ }^{8}$ y después latino, ${ }^{9}$ sustituyendo en gran medida a la memoria y a la palabra como elemento transmisor y verificador de los contenidos culturales: incluso las leyendas y mitos se escriben dando lugar a la primigenia producción literaria y científica en época griega. ${ }^{10}$

6 Vid

- Bonafante, J. đal. La neissancedesénitures Da andformeal'alphabe. París, 1994.

- Croatto, J.S. Orignyedunión dd alfabła Buenos Aires, 1968.

- Cross, F.M., "Origin and Early Evolution of the Alphabet", en AmeicanJaumal of Ardhaedogy. 1933, 37, pp. 8-29.

- Driver, G.R. Seriticuriting fromPidograph toAlfabet. Londres, 1976.

- Fevrier,J.G. "Los semitas y el alfabeto. Escrituras concretas y escrituras abstractas", en Laescritur rayla psidoǵa..., Op Cit, pp. 119-132.

- Hirschfeld, H. "Recent theories on the origin of the alphabet", en Jamal oftheRgal AsiaticSacidy. 1911, Londres, pp. 964-977.

- Logan, R.K. TheAlphabeEffet, theImpactof thephoneicalphabetontheDedqpmentofWestemCiviliza tion Nueva York, 1986, etcétera.

7 Algunas excepciones a lo dicho pueden verse en Kramer, S.N. LahistriaempiæaenSumer. Barcelona, 1985 .

8 - Burzachechi, M. "L'Aadozione dell' alphabeto nel mondo greco", en Lapardadd Passato 1976, 3, pp. 82-102.

- Cavallo, G. "Cultura scritta e conservazione del sapere: dalla Grecia Antica all'Occidente medievale", en Rossi, P. (Ed.). Lammma..., Op Cit Roma, 1988, pp. 29-67.

- Colonna, G. "La diffusione della scrittura", en Civiltà da Lazio Primitiva Roma, 1976, pp. $372-376$.

- Morrison, S. Pditicsand Scipt. Aspeets of authorityandfreedmin th dadqpment of Graeo Latin Scipt. Oxford, 1972.

- Susini, G. “Origini e diffusione dell' alfabeto greco", en Leionetentendl 'Univesitádi Bdoga Bologna, 1954.

9 Vid

- Bloch, R. "Etruscos y romanos. Problemas e historia de la escritura", en La ecaiturayla picdo ǵa..., Op Cit, Méjico, 1992, pp. 189-204.

- Cavallo, G. "Storia della scrittura e storia del libro nell' antichità greca e romana. Materiali per un studio", en Euphrosyne1988, 16, pp. 401-412.

- Iddm "Dal segno incompiuto al segno negato. Linee per una ricerca su alfabetismo, produzione e circolazione di cultura scritta in Italia nei primi secoli dell'Imperio", en AlfabdismoeCultura, Perugia, 1978, pp. 119-145.

- Cristofani, M. "Rapporto sulla diffusione della scrittura nell'Italia Antica", en Scittura eCiviltà, 1978,2, pp. 5-33, etc.

10 La poesía épica de Homero es, sin duda, el monumento cultural más importante que Grecia ha transmitido a Europa sobre la tradición escriturada. 


\section{Inestigaión Biblictedlógicav. 18 No. 36 enero/ junio de 2004}

Sin embargo, los procesos históricos de esta magnitud no son nunca revduaionarios, antes al contrario, las viejas tradiciones se funden con los nuevos usos sociales. De ahí que todavía en época imperial se custodiasen los documentos más solemnes en los templos y que fuera este requisito el que les otorgaba fhadenaa hubo que esperar a Justiniano para que se estableciese algo en apariencia tan imprescindible como la regulación pública de los formulismos de validación documental. ${ }^{11}$

Así pues, la escritura tardó muchísimo tiempo en romper las barreras socio-profesionales que circunscribían su uso al mundo del poder político, la iglesia, las élites sociales y determinados colectivos profesionales. Hubo que esperar al Renacimiento y su imprenta, cuando la confluencia de una serie de cambios técnicos, socio-económicos, culturales, políticos e incluso religiosos hicieron avanzar la altura @crita hasta romper con las constricciones anteriores y alcanzar a los grupos populares, en un proceso todavía hoy no terminado a escala mundial.

En esta extensión no sólo entraron en juego elementos estrictamente culturales o educacionales, sino también actitudes sociales nuevas y progresos tecnológicos que las facilitaron. Entre las primeras es evidente que la escritura enlazó con un nuevo modelo de hombre, la persona ilustradacomo sinónimo de individuo perteneciente a la élite social y, como contraposición, un descrédito absoluto, incluso religioso, por lo que llamaríamos altura tradidional o pqular. Entre las segundas, no cabe ninguna duda de la importancia jugada por determinados avances técnicos que redujeron los costes económicos del documento escrito, tales como la imprenta o la sustitución del pergamino porel papel. ${ }^{12}$

En cualquier caso, la producción documental comenzó un proceso de aumento exponencial, que todavía hoy no ha terminado, y el documento escrito desplazó paulatinamente a cualquier otro mecanismo para transmitir contenidos culturales, comunicar órdenes políticas o garantizar derechos públicos y privados. No en vano, es

11 Cfr. Dors, A. Doamentosyndariosen ed daeehoramanopost-dásica Madrid, 1964.

12 Para la historia de los soportes, Vid

- Asenjo, A. El papd ysufabricacón Madrid, 1961.

- Bergada, L. Lafabricacón de papd Madrid, 1945.

- Blum, A. La ratedupapier, Grenoble, 1946.

- Briquet, Charles-Moïse. "Notions practiques sur le papier", en LeBibliographeModame, 1905, IX, pp. 5-36.

- Calderini, A. TratadodePapirdoǵa Barcelona, 1963.

- Garcia Villada, Zacarías "Materiales e instrumentos de la escritura en la Antigüedad y en la Edad Media”, en RazónyFe 1919, t. LV, III, pp. 459-466.

- Gayoso Carreira, G. Histaria de papd en España Lugo, 1994.

- Montevechi, O. La Papirdoga Turín, 1973.

- Ragab, H. LePapyns El Cairo, 1980

- Romero Tallafigo, M. "Los soportes archivísticos a través de la historia, desde los sumerios hasta la actualidad”, en El papd ylastintasenla transmión delainfomaaón Huelva, 1992.

- Ryder, A. "Parchement: Its History, manufacture and composition", en Jamal oftheSodidyofArdivists 1964, 2, pp. 331-339.

- Valls I Subirà, O. Histona de papd enEspaña, sigosX-XIV, Madrid, 1978. 
precisamente durante el tránsito de la Edad Media a la Moderna, cuando se crean los primeros archivos públicos concebidos al modo moderno, no como simples acopios de documentos solemnes de cancillería, como eran los cartularios medievales o los primeros registros. El aumento de la producción documental, por otro lado, exigía de nuevas soluciones; ya no se podía confiar sin más la custodia de los documentos a los oficiales cortesanos, chancilleres y demás, que se responsabilizaban de la conscriptio diplomática. De ahí que las ordenanzas establezcan normas archivísticas expresas desde finales de laEdad Media. ${ }^{13}$

En definitiva, entendemos la cultura escrita como un factor apriorístico, que ha influido decididamente en el desarrollo de los Archivos.

\section{LA PRÁCTICA E CLESIÁST ICA}

Como hemos dicho, las prácticas religiosas y las iglesias o grupos sacerdotales en general tuvieron una importancia capital en el surgimiento y desarrollo de la alturaes citay en las primeras experiencias archivísticas. Los documentos escritos más antiguos que se conservan son frecuentemente de carácter religioso y sabemos que la escritura, en las primeras civilizaciones que la practicaron, se fraguó y desarrolló, más que en ningún otro ámbito, entre 'déigos. No vamos a repetir pues su papel en los primeros momentos de la historia de los archivos durante la Edad Antigua, lo que ahora nos ocupa es su participación directa -y, durante algún tiempo, casi exclusiva- en la génesis de los archivos a partir dela Edad Media. ${ }^{14}$

La Iglesia, no sólo la católica-y en esto podríamos remontarnos hasta las primeras civilizaciones con escritura-, sino prácticamente todas sin excepción, se basan en un conjunto articulado de preceptos que denominamos, usualmente, dotrina. Sucede, sin embargo, que esa doctrina, pese a su importancia, puede ser reinterpretada e incluso transmitida de forma parcial o subjetiva. De ahí el denodado empeño, detectable incluso entre los pueblos primitivos, por transmitirla de un modo unilateral y completo. La propia existencia de castas sacerdotales es, en buena medida, resultado de la necesidad de garantizar la pureza o la autenticidaddbotinal frente a hipotéticas desviaciones. Escribir los preceptos religiosos y garantizar que se conserven fue, desde

13 Uno de los ejemplos mejor conocidos acerca de la vinculación existente entre la profesionalización y la complejización de la maquinaria burocrática y la aparición de archivos es el del Consejo de Castilla. Una recopilación de instrucciones y ordenanzas puede verse en Dios, S. de Fuentesparad estur doda ConsejodeCastilla. Salamanca, 1986.

14 De la amplia bibliografía disponible sobre archivos eclesiásticos podemos destacar:

- Ambrosini, M.L. Losarchivos seeteos de Vaticama Barcelona, 1973.

- Badini, G. Ardivi eChiesa, Bolonia. 1989.

- Bordonau y Mas, M. Los ardhivos edesásticos españdes Madrid, 1955.

- Fernández Catón, J.Mª Los archivos dela Igeesia en España. León, 1978.

- Rubio Merino, P. Archivos elesiásticos Nociones básicas Mérida, 1998.

- idem Ardhivos edesásticos Descipión, prdblemática, lejsiación México, 1991. 


\section{Investigaión Biblidteclógica v. 18 No. 36 enero/ junio de 2004}

el propio surgimiento de la escritura, una prioridad para los grupos sacerdotales, incluso en épocas, como sucedió durante la Edad Media, de retroceso general de la cultura escrita, cuando, en la práctica, los textos conservados circulaban casi exclusivamente entre clérigos.

Desde las inscripciones grabadas sobre las paredes de los templos egipcios hasta el Archivo Secreto Vaticano existe un tenaz esfuerzo eclesiástico por dotar al documento sacro de intemporalidad, por liberarlo de un proceso evidente en otras facetas de la vida social: la reinterpretación, la adaptación a nuevas necesidades o nuevos gustos. Y es precisamente, como decimos, en épocas de declive -como la Edad Media-o de poco desarrollo de la cultura escrita, cuando el archivo eclesiástico pasa a un primerplano.

En otro orden de cosas, el documento escrito se vinculará hasta los albores del mundo contemporáneo con el mundo de la religión: desde la práctica romana de conservar los documentos en los templos hasta la invocación que preside los documentos solemnes medievales y modernos, pasando por la costumbre de custodiar los archivos municipales, nobiliarios e incluso reales en iglesias y monasterios hasta la Edad Moderna. Al mismo tiempo, desde un punto de vista cultural, buena parte de la tradiánsacaque envuelve al documento escrito proviene de su tradición eclesiástica: la palabra de Dios se sacraliza mediante su escriturado en el libro sagrado.

Sin embargo, junto a estos aspectos doctrinales y culturales, la Iglesia jugó un papel importantísimo de cara a la ulterior configuración de los Estados Modernos europeos. Como es sabido, la institución eclesiástica fue capaz de mantener un alto grado de cohesión y complejidad administrativa cuando en su entorno seglar, durante la Alta Edad Media, la tendencia era la opuesta. La administración eclesiástica y su concreción en archivos parroquiales, conventuales y de otras instancias servirá de modelo a la Corte y a las casas nobiliarias cuando éstas comiencen a desarrollar articulaciones jurídico-administrativas complejas: bien sea desde la recepción del derecho romano (basado en el documento escrito como elemento probatorio, quadnonestin adanonestinmund) hasta la creación de sistemas de registros de documentos de cancillería, a imitación de los cartulanioseclesiásticos y otras colecciones -tescrosdecartas-, pasando por la propia formalización de tipos documentales -piénsese, por ejemplo, en el famoso Privilegio Rodado, una adaptación de un tipo documental papal por la cancillería castellano-leonesa en el siglo XI- o procedimientos de expedición.

Por último, el Concilio de Trento, presionado por la necesidad de combatir la herejía y fiscalizar con rigor la ortodoxia de las prácticas católicas en toda la cristiandad, forzará la creación de la actual red de archivos parroquiales y episcopales, obligando a cabildos y obispados a mantener actualizados los registros de cumplimiento de las obligaciones sacramentales (los famosos librosdecasados, vdadbs, commiónpasaul, difuntosy bautismos), las cuentas de la Iglesia (librosdefábricay de tazmáas), la gestión de obras pías, aniversarios y capellanías, las labores de control pastoral desde el Obispado (visitaspastarales) y las actas de las reuniones capitulares, entre otras series documentales, quehoy conforman una página esencial de nuestros archivos históricos. 


\section{LA SALVAGUARD A Y GARANTIIA JURÍDICA}

Otro de los grandes factores que han condicionado la aparición y desarrollo de los archivos ha sido, desde los mismos orígenes de la cultura escrita, una doble necesidad: la de poder asegurarse la formalización de sus órdenes y prerrogativas, y la de salvaguardarlos derechos delos particulares frente a hipotéticosincumplimientos ajenos.

En este sentido, entre los primeros documentos escritos conservados también encontramos, junto a los eclesiásticos, otros de carácter político. Hacemos referencia, fundamentalmente, a disposiciones de gobierno. Téngase en cuenta que la ley no necesariamente ha de estar escrita; de hecho, en las tradiciones judiciales populares, es raro que lo esté antes del Renacimiento, ${ }_{15}^{15}$ pero sí precisa estarlo cuando lo que se legisla u ordena no está basado en la costumbre, sino que es una disposición unilateral que parte de las autoridades y aspira a ser obedecida sin dar lugar a interpretaciones interesadas o adaptaciones aintereses cambiantes.

No en vano, buena parte de los documentos públicos que conservamos de la Edad Media y periodos anteriores son documentos dispositivos y repertorios legales, con los que se hizo el mayor esfuerzo posible de cara a su perdurabilidad, y gracias a ello han llegado hasta nosotros. Ya en el siglo XVII, toda una disciplina, ${ }^{16}$ la diplomática, se configuró en torno a esta concepción del documento como instrumento jurídico de creación, reconocimiento o renovación de derechos, estableciendo a esta clase documental como el testimonio escrito por excelencia, el doumentodiplanática El surgimiento de esta disciplina no es inteligible sin la preexistencia de todo un entramado jurídico-cultural que convirtió de forma paulatina al documento escrito como garantía del reconocimiento de cualquier acto jurídico: las ordenanzas sobre el Registro de Cancillería de los Reyes Católicos, la obligatoriedad establecida por Carlos I que obligó a los ayuntamientos a escriturar sus actas capitulares, ordenanzas y a dotarse de un archivo municipal, las múltiples y variadas instrucciones dirigidas a los organismos de la Corte desde época de Juan I regulando los procedimientos documentales, etcétera, son todos ellos indicadores de un nuevo concepto jurídico-cultural que elevaba el documento escrito a un papel estelar en la vida jurídica y política.

Cuando descendemos todavía más, para adentrarnos en la realidad archivística desde la Edad Media, descubrimos que no todo documento escrito se conservaba, sino que, en realidad, se llevaba a cabo un archivo selectivo de algunos de ellos: $¿ \mathrm{Cu}$ áles eran éstos? Pues por lo que podemos deducir de los fondos que han llegado hasta nosotros, hasta los albores de la Edad Moderna sólo se conservan de forma más o menos sistemática los documentos constitutivosdedkehoy, cuando éstos faltaban, los

15 Vid Lorenzo Cadarso, P.L. La dbamentaiónjudidal enla época delosAustrias, Cáceres, 1999; idam "Fuentes municipales para el estudio de las tradiciones judiciales medievales y modernas castellanas" En Martos, E. (Ed.). Tradicoón costumbreydaechoconsududinanioenExtremadurayd Alentgo Mérida, 2000.

16 La obra que suele considerarse como iniciadora de esta disciplina es el libro de Mabillon, J. Derediplanática libri sex, es decir, Seis libros sobre la Diplomática. 


\section{Inestigacón Biblidtecdógica v. 18 No. 36 enero/ junio de 2004}

recogitivoso los de renovacón Todavía bien entrado el siglo XVI la conservación de otro tipo de documentos, básicamente de los que llamaríamos de trámite administrativo en términos jurídicos y doumetoslatosen la terminología diplomática, es nula o muy parcial. Es decir, aquellos papeles que no servían directamente como garantía de derecho, en la mayoría de las ocasiones, eran considerados inútiles y destruidos sin mayores contemplaciones.

Desde la Baja Edad Media -en España habría que considerar como momento epigonal la labor legislativa de Alfonso X en el siglo XIII-, ${ }^{17}$ el proceso de reequióndel derecho romano-canónico, transmitido a través de la recopilación justiniana, propició -ya lo decíamos antes-la consideración del documento escrito como el principal instrumento prdbatariode cualquier derecho público o privado. Este es uno de los procesos que impulsará a otro de los factores que explican la proliferación de documentos de archivo en el mundo occidental: el ndariadb ${ }^{18}$

La existencia de un oficial público que acredita la autenticidad del proceso de escriturado de un documento y que se responsabiliza luego de su correcta custodia reforzó, sin lugar a dudas, el papel del documento escrito -y por extensión, de su archivado- como instrumento jurídico de garantía y salvaguarda de derechos, más allá incluso del universo de los poderes públicos, para alcanzar también al de la vida privada en la que actos tan íntimos como el matrimonio, el nacimiento o la muerte terminarían por tener también su concreción escrita y su documento de archivo.

En definitiva, escribanos y notarios actuaron, durante el tránsito de la Alta a la Baja Edad Media, como cuñas de la alturaexataen ámbitos hasta entonces prácticamente ajenos a ella, como pudieron ser los concejos, ${ }^{19}$ los señoríos laicos, ${ }^{20}$ o el mundo de los negocios mercantiles. ${ }^{21}$ La constitución de la red de archivos señoriales y municipales, tal y como hoy la concebimos, hubiese sido extremadamente complicada sin los cambios que en la gestión administrativa introdujo el notariado bajomedieval y moderno.

17 Específicamente sobre el tema que nos ocupa, véase Bono Huerta, J. "La legislación notarial de Alfonso X el Sabio: sus características”, en AnalesdelaAcadamiadl Notariadb1984, XXVII, pp. 30-43. A nivel general europeo puede verse: Carlin, M.L. Lapénátrationdudraitramaindanslesadesdelapractiqueprovençale(XI-XIIIesiède). París, 1967.

18 Una introducción general en Amelotti, M. Peruna staia dd notaiatomeridionale Roma, 1982. Más centrada en España, la ya citada: Bono, J. Histariadd deechondarial españd. Madrid, 1979-82, 2 vols. Desde una perspectiva más archivística: Alvarez Coca, M.J., "La fe pública en España. Registros y notarios. Sus fondos, organización y descripción", en Bdéín dela ANABAD. 1987, XXXVI, pp. 7-66.

19 Vid Corral García, E. El escibanodeconejoenla Corana deCastilla, ss XI-XVII. Burgos, 1987.

20 Vid Flórez de Quiñónez, V. “Señores y escribanos”, en Reista deDerehoNotaial. 1968, LX, pp. 5-39.

21 Vid Conde y Delgado de Molina, R. Estudiotipdógiøodela dbamentadóncomeraal yfinanieramedieal. Fuentes de Archivodela Corana deAragón Valencia, 1981. 


\section{LA BUROCRACIA: EL ARCH IVO COMO INST RUMENTO POLÍTICO}

Cuando se ejerce el poder por parte de cualquier tipo de autoridad política, éste se fundamenta convencionalmente en dos ámbitos diferentes, aunque en la práctica no siempre sea fácil distinguirlos: los fundamentosdesdberaníay los instrumentosdegerciaioda podk. Los primeros son los referentes jurídicos, éticos, religiosos o de otro tipo que legitiman su concreción institucional y actúan como marcos de constricción del ejercicio del poder. Los segundos son las herramientas y prácticas políticas que se emplean para tomar las decisiones, comunicarlas y hacer efectivo su cumplimiento. La información ha jugado históricamente un papel capital en todo este complejo entramado de referentes teóricos y prácticas políticas al que nos referimos. Sin embargo, dicha información, como decíamos al comienzo, no necesariamente ha de concretarse en documentos escritos, y mucho menos en registros organizados. En consecuencia, para que el archivo pase a convertirse en un instrumento de poder eficaz precisa, a modo de precondición, no sólo la extensión de la alturaescita, sino también de la confluencia de procesos mucho más concretos, aunque bien podríamos sintentizarlos en un solo concepto: la burorada

Efectivamente, por lo que sabemos del papel jugado por los archivos en diferentes formas políticas, su desarrollo parece venir ligado a la complejidad de las mismas, a unas determinadas circunstancias en las que el oficial público se convierte en un mero eslabón de una imbricada red administrativa. Si comparamos, por ejemplo, los archivos reales medievales con los modernos vemos un paralelismo evidente entre el volumen de oficiales públicos y la complejidad de los procedimientos administrativos, por un lado, y el interés de la Corona por conservar los documentos en archivos, por otro. Hasta entonces, los oficiales medievales responsables de la expedición de documentos eran quienes se hacían cargo de la documentación administrativaque se generaba durante los procesos políticos de toma de decisiones, y, asimismo, la Corona sólo se preocupaba-y esto en fechas ya bajomedievales- por conservar copias en registros de los documentos solemnes de cancillerías esto es, aquéllos que contenían disposiciones consideradasimportantes.

La centralización de la soberanía presupone el aumento de la producción documental y una paulatina ampliación de los asuntos sobre los que hay que tomar decisiones. Para hacerlo se recurrirá a personal técnico -letrados universitarios, escribanos, simples amanuenses, etcétera, durante la construcción del Estado Absoluto, por ejemplo-, cuyo trabajo, si se desea poder controlar, habrá de estar sujeto a proedimiertosperfectamente regulados, susceptibles de permitir la detección de arbitrariedades o ineficacias entre el funcionariado. En Castilla, de este modo, se establecerán dos grandes procedimientos entre los siglos XIV-XVI -la fecha de origen no está claraque recibieron el nombre de víadeproesoy víadexpediente, y fue a partir de estos sistemas de tramitación de los asuntos cuando se multiplicó el volumen de documentación expedida, no sólo de documentos dispositivos, sino sobre todo de los de trámite 


\section{Investigaión Biblidtecdógica v. 18 No. 36 enero/ junio de 2004}

administrativo, que, en realidad, sólo eran conocidos y utilizados por el propio engranaje burocrático de la administración. ${ }^{22}$

Por otro lado, a partir de finales del siglo XV -por lo que se refiere a Castilla- diversas Instrucionesy Ordenanzasregularán los registros, los libros copiadores, los archivos administrativos de Secretarías y Escribanías de Cámara y, por último, ya a comienzos del XVI, se crearán los primeros archivos reales propiamente dichos, cuando la capacidad de almacenamiento en las instalaciones de los Consejos se vio desbordada. Hacemos particular referencia a los Archivos de la Chancillería de Valladolid y al de Simancas. La historia que venimos contando de forma tan sucinta para la Corona de Castilla se repitió, con los procesos circunstanciales pertinentes, siempre que se configuró una administración estatal. 23

$\mathrm{El}$ archivo, por tanto, surge como una necesidad administrativa para un ejercicio del poder más eficaz, pero ésta es una explicación todavía incompleta: ¿Qué aporta concretamente el archivo a la eficacia política? Veámoslo de manera más analítica:

1. Favorece el nigrylaagilidadadministrativa, puesto que los oficiales disponen de un punto de información para conocer los antecedentes de los asuntos que están tramitando y para organizar adecuadamente grandes volúmenes de documentos administrativos gestionados por entidades distintas o llegados de diferentes procedencias en fechas diversas.

2. Permite un contrd jerarquizadbdelasadividadesgubemativasojudidalesmediante diversos sistemas de inspección -recuérdense, por ejemplo, los juicios dereidania en Castilla o las visitas y pesquisas que se realizaban periódicamente-, al poder rastrearse el funcionamiento de una oficina o el trabajo en ella de un oficial a través de las referencias documentales conservadas.

3. Auspicia un contrd sobre el conjunto de los particulares que, en algún momento, han entrado en contacto con la Administración.

22 Sobre el origen del expediente, vid

- Dios, S. de. El ConsejoReal deCasilla. Salamanca, 1986.

- Gómez, M. Foma yexpedicón de doumentoenla Seretanía deEstadbydd ConøjodeIndias Sevilla, 1993.

- Villapalos, G. Losrearsos contra los ados degdiemoenla Baja EdadMedia, Madrid, 1971.

23 Para los orígenes medievales, Vid

- Casado Quintanilla, B. "Poder y escritura en la Edad Media", en Espado, Tiempoyfoma 1995, Serie III, t. 8, pp. 143-168.

- Clanchy, M.T. "Literacy, law and the power of the State”, en Cultureetidédogiedanslagenèsedel'Etat modame Roma: Ecole française de Rome, 1985, pp. 25-34.

- García Lobo, V. Losmedios decommicadónsoial enla EdadMedia. La commicadónpubiaitaria Lección inaugural del curso académico 1991-1992. León: Universidad de León, 1991.

- Hajnal, I. "Le rôle social de l'écriture et l'evolution européenne", en Reuredel'Institut Socidogique Sdway. 1934. XIV, pp. 23-53 y 253-282.

- Petrucci, A. "Storia della scrittura e della società", en AnalfabetismoeCulturaScritta, 1989, 2 , nueva serie, pp. 47-51. 
En conclusión, el archivo se nos presenta, por un lado, como una necesidad generada por la configuración de la soberanía en formas estatales o preestatales de cara a su propio funcionamiento, pero también como un instrumento de poder, de control político interno y externo. Esta doble realidad explica una conceppoónpuramenteutilitaria einfomadional da ardivg que de hecho fundamenta, todavía hoy en cierta medida, algunas de las propuestas teóricas más recientes de la archivística.

\section{LA MEMORIA HIST ÓRICA}

Que los fondos de unos archivos diseñados para servir a la administración se hayan conservado más allá de las necesidades que los gestaron es, desde luego, una novedad histórica que necesariamente hemos de vincular con una serie de cambios socio-culturales, políticos y de otro tipo, fraguados en el mundo occidental -básicamente europeo-durante los últimos siglos. Lo más usual en todos los archivos surgidos en ámbitos político-administrativos (desde las ciudades sumerias a Roma) es que una vez perdida su utilidadadministrativaterminaran siendo destruidos. Lo que ha ocurrido en nuestro entorno cultural es, desde luego, una novedad histórica relativamente reciente. ${ }^{24}$

La valoración del documento como instrumento verificador del discurso histórico se fraguó en un campo, en principio, ajeno al mundo de la administración civil y de sus archivos: se gestó entre eclesiásticos preocupados por cuestiones hagiográficas y de Historia de la Iglesia durante el siglo XVII, cuando surgió la disciplina que conocemos como diplomática, a la que la archivística se mantendría vinculada durante bastante tiempo.

Deslindar los documentos auténticos de aquéllos que no lo eran no fue una preocupación acuciante durante el mundo clásico greco-romano, cuyo sistema de autenticación documental se basaba en la custodia de los documentos en oficinas públicas y templos, entidades que formalizaban jurídicamente el documento. Parece ser que

24 Vid

- Cavallo, G. Cultura scrittaeconservazionedd sapere dalla Greciaanticaall'ocidentemedievale Lamemora de sapere Fomedi conservazioneestrutturearganizzativedall'antichita a ogj: Roma-Bologna. 1988, pp. $29-67$.

- Le Goff, J. “Documento/Monumento”. Irarg்1989, 2, pp. 103-131.

- Lodolini, E. Ardivística. Prinapiosyprdbemas Madrid, 1993.

- Peiró Martín, I. y Pasamar Alzuría, G. LaEsadaSuperiordeDiplanática Losarchiverosenlahistaio grafía españda contemparán Madrid, 1996.

- Pratesi, A. "Diplomatica ed archivistica: due disciplini a confronto", en Ardivi perlastaia, 1992, 2, pp. 3-10.

- Vázquez de Parga, J. “Los benedictinos y la erudición histórica”, en ReistadeArdivos, Biblidtecasy Musees 1979, 82, pp. 395-406.

- VV.AA. Enudiánydisarsohistáica Lasinstituaiones arropeas (ss XVIII-XIX). Valencia, 1993.

- Zannini Rosiello, I. Archiviememmiestaica Bolonia, 1987. 


\section{Inestigacón Biblidtecdógica v. 18 No. 36 enero/ junio de 2004}

no fue sino hasta el siglo VI cuando se dictaron normas expresas acerca de las formalidades que deberían reunir los documentos para evitar falsificaciones y poder utilizarlos como pruebajurídica. ${ }^{25}$

Como en tantas otras cosas, fue la Curia Pontificia la encargada de establecer las primeras normas para regular y determinar la autenticidad documental. Así, durante el pontificado de Inocencio III (1198-1216) y a raíz de un agrio debate en torno a un documento falso presentado ante el Cabildo de la Iglesia de Milán, se regularon los formalismos que habían de presidir la redacción y transcripción de los documentos expedidos por la cancillería vaticana, ${ }^{26}$ así como el método que habría de seguirse para examinary corroborar la autenticidad delos documentos. ${ }^{27}$

La labor de los peritos de la cancillería papal, en realidad, sólo era aplicable a documentos contemporáneos suyos, pero resultaban ineficaces para determinar la autenticidad de diplomas antiguos, puesto que se carecía de conocimientos históricos suficientes sobre las prácticas documentales anteriores. ${ }^{28}$ Fue en el Renacimiento cuando vino a suplirse, bien que parcialmente, esta importante limitación del estudio de la autenticidad gracias al eruditismo histórico que caracterizará a los humanistas desde fechas muy tempranas. ${ }^{29}$ Así, el convulso tránsito de la Edad Media a la Modernidad, plagado de polémicas religiosas y políticas, propició el esfuerzo de eruditos en el acopio de documentos que justificasen sus posturas..$^{30}$

En el siglo XVII, las dificultosas negociaciones de la Paz de Westfalia se vinieron a sumar a las continuas disensiones entre órdenes religiosas que ya venían de atrás. Fue la época de las llamadas bdladiplamatica, en las que las disputas sobre los documentos que acreditaban derechos jurisdiccionales o de soberanía terminaron por tener mayorpeso que los acostumbrados einterminables debates teológicos.

\section{Cfr. Dors, A. Doumentosyndariosen d daechoromamopost-dásica Op Cit.}

26 Vid Delisle, L. "Memoire sur les actes d'Inocent III", en Biblidhequedel'EcdedesChartes 1858, 4, pp. $1-73$.

27 Aunque se limitaban a algunos caracteres externos del documento, Inocencio III estaba creando las bases iniciales para el análisis diplomático de la autenticidad documental: Determinar si el sello es auténtico o está falsificado, si el hilo que lo sujeta es legítimo, si el sello ha sido desatado de su documento primitivo para unirlo al falso, si en el texto del documento hay raspaduras que hagan sospechar alguna alteración en la naturaleza del documento, etcétera. (Vid. Batelli, G. Lejioni d Paleografia Vaticano, 1949, cap. III. El texto de las normas puede consultarse en Migne, A. Patrdoga latima 216, cols. 1218 B-1219 A.).

28 Vid Bouard, A. de. Manud deDiplomatique París, 1929, I, p. 20.

29 Emblemático de esta actitud fue el famoso dictamen que Petrarca remitió a Carlos IV en 1361 mostrando la falsedad de dos supuestos privilegios expedidos por Julio César y Nerón, demostrándolo recurriendo a los formulismos de la data y la intitulación. (Vid. Petrarca, F. Eṕstdadefalstate privileä AustriamabImpeioeximetes Basilea, 1855, Libro XV, epístola 5, p. 955).

30 Como los falsos Decretales que el protestante Matías Flach Francowitz, conocido como Flacius Sllirycus, incluyó en su HistoriaEdesiásticapara justificar la Reforma; y la réplica del Cardenal Baronio, en la que por primera vez se editaban y citaban los documentos con rigor (Vid Baronius, C. Anmales edesiastia a Chistonatoadanmum1198. Roma, 1593-1607). 
Fue destacada, en este sentido, la personalidad de Daniel Von Papenbroch, figura clave en los orígenes de la Diplomática Científica, ${ }^{31}$ quien expuso su método de autenticidad de los documentos en crítica a la documentación que guardaban los benedictinos franceses de la Congregación de San Mauro. ${ }^{32}$ La respuesta benedictina le fue encomendada a Mabillon, que en 1681 publicó su Deredplamaticalibri sex, en la que se nominaba a la disciplina y se la definía como arsseundi antiguadiplomatadeemedi veraafalsis, es decir, dedicada a analizar los documentos antiguos y valorar su autenticidad o falsedad. Para Mabillon, y ésta sería una concepción llamada a perdurar, el carácter jurídico del documento primaba sobre cualquier otro aspecto o contenido del mismo, su escriturado o su dimensión histórica, lingüística, literaria, etcétera. En esta línea, Oliver Legipont definía los documentos diplomáticos a mediados del XVIII como "[...] armas legales para defender los derechos y facultades, y también para perpetuar legaly públicamentela memoria delas cosas sucedidas". ${ }^{33}$

El euditismode los siglos XVII y, sobre todo, XVIII, no fue una cuestión puramente cientificista. Detrás de la Congregación Benedictina de Valladolid, del Padre Flórez o de Mayans, por ejemplo, estaban también los intereses políticos de unas monarquías europeas cada vez más preocupadas por cuestiones relacionadas con lo que hoy llamaríamos quiniónpública. Y junto a los primeros trabajos de diplomática en España estuvo, como muestra, la figura del Marqués de la Ensenada, en cuyo proyecto político estaba la españdizacónde la dinastía borbónica y los más inmediatos intereses relacionados con el Concordato, que habría de regular las relaciones entre España y la Santa Sede. Pero fue probablemente la fundación del Archivo de Indias el ejemplo más acabado de cómo el valor histórico del documento empezaba a ser un asunto de

31 En 1629 moría en Amberes Heriberto Roswey, jesuita holandés que se había dedicado a los estudios de tipo hagiográfico, dejando un manuscrito de vidas de santos y múltiples notas y copias. La Compañía encargó a Jean Bolland que examinase tales textos, y éste logró de sus superiores apoyo para editarlos siguiendo el orden del calendario. Se encargó el proyecto a la Casa de Amberes, que para 1643 publicaba los tres primeros volúmenes, correspondientes al mes de enero, del AdaSane tonum Quince años después, en 1658 aparecieron los tres volúmenes de febrero; y al año siguiente se incorporó al equipo Daniel Von Papenbroch. Vid

- Le Haye, H. de. L' 'amedesBdlandistes Bruselas, 1920; 1́dam “Papenbroch". BibliographieNationa le 1901, XVI, pp. 581-589.

- Poncellet, A. "Mabillon et Papenbroch", en ArdivedelaFranceMonastique 1908, V, pp. 169-175.

- Scaduto, M. “Jean Bolland”, en Enidqpedia Cattdica. 1781-1782, Vol. III, pp. 23-46.

- Villaplana, M.A. "Correspondencia de Papenbroch con el marqués de Mondéjar", en Hispania Saca. 1975, 25, pp. 393-349).

32 Los benedictinos franceses de la Congregación de San Mauro se hallaban a la sazón embarcados en un no menos ambicioso proyecto bajo el título GaliaChistiana, en torno al cual trabajaban expertos de primerísima fila y con objetivos paralelos, puesto que tenía un importante componente hagiográfico. Papenbroch incluyó una introducción al segundo volumen de abril titulada Propjaam antiquaniumarcaveriacfalsi discimeninveustismembranis, en la cual, tras exponer su método para analizar la autenticidad de los documentos, concluía tachando de falsificaciones al grueso de los diplomas merovingios franceses, precisamente los que custodiaba la Abadía maurista de Saint Denís.

33 Legipont, O. Itimerarioenquesecontiened modbdehacerconutilidadlosviagesaCartesestrangerascondosdisertaciones, lapimerasobred modbdedrdenary yomponerumalibreía, la segundasobred modbdeponerardenenun ardiva Valencia, 1759, p. 295. 


\section{Investigaión Biblidteclógica v. 18 No. 36 enero/ junio de 2004}

interés político: su fundación respondió, como es sabido, al deseo de escribir una his toriadelacolonizaciónespañola alternativa a la divulgada por la Leyenda Negra.

El teniaismoyd aentifiasmodel siglo XIX, unido a la concepción empirista de la historia, que convertía al documento escrito en el protagonista del trabajo técnico del historiador y del discurso histórico, aportaría a la archivística un sustrato técnico imprescindible de cara a su configuración como ciencia. Sin embargo, lo que ahora nos interesa prioritariamente no es la vertiente técnica o doctrinal de la disciplina, sino el entorno sociocultural en el que se fraguaron sus primeras formulaciones científicas.

¿Qué esperaban de los archivos los hombres de este periodo fundacional de la archivística como ciencia? Lo primero que hay que decir es que otorgaron a los archivos y a sus fondos una importancia capital, de ahílos enormes esfuerzos que se hicieron en la creación de archivos históricos, en la organización de escuelas y cursos de formación, en la recuperación de fondos dispersos o en peligro de destrucción, en la creación de cuerpos profesionales, en la reflexión acerca del mejor modo de gestionar los centros y areejarlospapdes-como decían los españoles de mediados del XIXy otras labores sin las que, probablemente, buena parte de nuestro patrimonio documental se hubiese perdido irremisiblemente. Todo este esfuerzo se basaba en una serie deideas políticas y científicas que podríamos sintetizar del siguiente modo:

1. La coneqpióndentifiastadelahistaia que para ser tal habrá de estar basada en fuentes verificables, esto es, en documentos de archivo localizables por quien desee corroborar su autenticidad. Para ello no sólo es necesario que se conserven los documentos antiguos, sino que resulta imprescindible que sean accesibles a los investigadores y que estén adecuadamente clasificados y descritos.

2. LaHistariaesuninstrumentodeprogresoscail, altural ypdítica, una herramienta con la que educar a la sociedad -la Historia como magistervitae-, un referentecon el que explicar-y predecir-la senda de progesoque ha caracterizado a la humanidad desde el paleolítico hasta un futuro más o menos utópico; y, por último, un amapdítica con la que legitimar y caracterizar los discursos nacionalistas, desde el carádterdelos puddos hasta sus derechos nacionales.

3. La valoración en sí misma de lo que se dio en llamar mumentos es decir, del patrimonio histórico como bien público, como una cuestión de interés colectivo de tipo cultural. No debe olvidarse que, junto a los archivos, en esta misma época se planifican y realizan las primeras grandes campañas arqueológicas, se inicia la práctica de la restauración con intencionalidad conservacionista e historicista, se crean los primeros museos, etcétera.

\section{LA FUNCIÓN INFORMATIVA}

Por último, no por evidente, hemos de olvidar una noción que consideramos de base para la comprensión de la archivística en su última etapa: la funcóninfomativade la documentación archivística, donde el ejercicio jurídico y de garantía de derechos y el uso dela memoria histórica se unifican. 
Durante la época moderna fue la propia administración la que empleó, en la mayoría de las ocasiones de forma coercitiva, la función informativa de la documentación archivística. Más tarde, durante los siglos XVIII y XIX, con la irrupción de las corrientes racionalistas, la pasión romanticista y nacionalista, o las reformas liberales y el posterior acomodo a las desamortizaciones y centralización hicieron que fueran los investigadores y los interesados por la historia los principales usuarios de los recursos informativos ubicados en los archivos. Sólo en la segunda mitad del siglo XX, y no siempre, la función informativa se generaliza. Es entonces, y en un panorama que se corresponde con la denominada archivísticaintegral, cuando surgen políticas archivísticas encaminadas al tratamiento global de los conjuntos orgánicos documentales. ${ }^{34}$ Todo ello intentaremos dejarlo explicitado en las líneas que siguen.

Ciertamente, en términos generales, los documentos archivísticos traspasan información, ya sea ésta de carácter legal, administrativo, financiero, etcétera, si bien, estamos de acuerdo con Lodolini cuando afirma que el conjunto orgánico de documentos transmite mayor información que el documento aisladamente. Al margen del debate por lo primigenio, si organicidad documental o función informativa, el objetivo último consiste en salvaguardar la información al potencial usuario. Eso sí, acentuando en las múltiples perspectivas, un método basado en la continuidad de las intervenciones del gestor documental o archivero. ${ }^{35}$

A nuestro entender, tres resultan ser los elementos con los que podemos contextualizar la función informativa a la que venimos haciendo referencia:

1. Lacomienteintegradara En medio de las posibles contradicciones, se suscitan soluciones unificadoras, derribándose la segmentación entre gestióndedbamentosy administracóndearchivos, y reduciéndose las distancias externas con otras disciplinas informativas.

2. La fomacón coniliada cond restodelasprofesiones delainfomadón El archivo, pues, como una más de las posibles unidades de información. Sin embargo, no podemos obviar aquí la conflictividad que resulta de establecer espacios diferenciados basados en las muchas particularidades. Así, la armonización natural-factible a través de la función informativa- basa su afianzamiento en una síntesis de contraposiciones. El resultado, posiblemente, no sea tanto el reposo estático cuanto el equilibrio dinámico de contrapesos.

34 Como señala Roberge: “es necesario que los profesionales de la gestión de la información administrativa y de los archivos se unan en una aproximación servicio-usuario elaborando un método riguroso, sistémico (que hace alusión a la noción de sistema) y sistemático (metódico, estructurado, que no deja nada al azar), sin olvidar las técnicas propias de la profesión, e inscribiendo esta actuación en una aplicación global de la gestión de los recursos informativos de la organización" (roberge, M. "La gestión de la calidad de lo archivos", en Tabula 1994, n 3, p. 117).

35 Vid

- Lodolini, E. “La gestion des documents et l'Archivistique”, en Dureance, J. (Comp.). Themanage mett of recordaedinfomation Paris: K.G. Saur, 1980, pp. 145-160.

- Cruz Mundet, J.R. Manual deArdhivística Madrid: Fundación Germán Sánchez Ruipérez, 1994, pp. 67-77. 


\section{Investigacón Biblideedógica v. 18 No. 36 enero/ junio de 2004}

\section{Laconstatacióndlimpactodelasteendoǵasdelainfomación comffactordavesdaredámbito}

archivística Entendemos que la tecnología ha dejado de ser algo competencial de otras disciplinas para inmiscuirse en los principios y métodos archivísticos. En este sentido, la tecnología se desvela como elemento armonizador. Diríamos que, dadas las características pragmáticas de la época, se produce una obligada voluntad de inserción basada en el criterio de eficacia y operatividad que es esencialmente tecnológico. ${ }^{36}$

Por otro lado, el despliegue de la función informativa de la documentación archivística ha estado mediatizado por la vinculación directa que sostiene con el desarrollo de la documentación administrativa, pública y privada, y su metodología de gestión. En definitiva, el archivo, como unidad informativa, forma parte esencial de las funcionesinformativas de la administración y de la empresa privada.

En este sentido, conviene recordar que hoy la legitimación viene dada por la eficacia. Se ha de ser eficaz o, de lo contrario, no se es válido. ${ }^{37}$ Pues bien, asistimos, en este contexto, a una vinculación entre la función informativa de la documentación y los servicios de calidad, entendidos como gestión eficaz de los recursos informativos. Fruto de todo ello es una administración pública reforzada con sistemas informativos en expansión y gestores de lainformación administrativa..$^{38}$

Relacionado con lo dicho, en el análisis de la administración y la generación de documentación, podemos señalar brevemente el siguiente cuadro de novedades:

1. Una progresiva compartimentación, la creciente asunción de atribuciones y funciones, y un aumento espectacular de la producción documental que deviene en una mayor complejidad de su gestión. ${ }^{39}$

2. Una multiplicidad de soportes documentales que el gestor de la información debe preservary conservar en los archivos administrativos para su consulta y servicio. ${ }^{40}$

36 Todo lo que en el saber constituido no sea traducible a los códigos tecnológicos será dejado de lado. Y es más, la orientación de las nuevas investigaciones se subordinará a la condición de traducibilidad de los eventuales resultados a un lenguaje máquina. En consecuencia, y en palabras de Lyotard, "losproductores dd sabe, lomismoquesusutilizadores, debenyddberán poseer losmediosdetraduara esoslengrajesloquebuscan, losunosal inventar, losctrosal aprenda".1987. (Cfr. Lyotard, J.F. La condicón postmodema Madrid. Cátedra, 1987, pp. 13-19. Una explicación adaptada en: Vivas Moreno, A. "La ‘legitimación del saber' en las nuevas formas de comunicación científica”, en AdasddXV Cdoquio AIB(AsoiationIntemationaledeBiblidogie) yI CdoquioAEB(AsoiaiónespañdadeBiblidoǵa): Lasnuevas formas decommicacón deentífica. Salamanca: Universidad de Salamanca, 2000 (En CD-ROM)).

$37 \mathrm{Y}$ ello, a pesar de que el criterio de operatividad no es pertinente para juzgar lo justo o lo verdadero.(Ibádem)

38 Cfr. Hackney, R.A.: Mcbride, N.K. The efficacy of information systems in the public sector. Issues in the public sector", en Intemational Jaumal ofPublicSetorManagment. 1995, vol. 18, nº 6, pp. 17-29.

39 Cfr. Chaín Navarro, C. Gestión deinformadón enlasarganizadones Murcia: DM., 1997, pp. 45 y ss.

40 Crr. Antequera Borredá, R. "Archivos Administrativos. Buscando su lugar en la Sociedad de las Tecnologías de la Información”, en Médodos deInfomaaión Enero-marzo, 1998 Vol. 5, № 22-23 (http://www.metodosdeinformacion.com/documentos/1998-22-51.pdf). 
3. El mayor uso de las nuevas tecnologías, que incide en la elaboración de documentos y el tratamiento de la información (producción y gestión de documentos electrónicos)..$^{41}$

4. Importantes cambios en los métodos de trabajo, siempre dificultados por la condición administrativa, informativa y jurídica de la documentación. ${ }^{42}$

5. Modificaciones en la tipología de los usuarios externos de los archivos y en el tipo de demandas con relación a la documentación pública. ${ }^{43}$

En consecuencia, en esta inestabilidad -originada por la propia evolución-los archivos no se están viendo inalterados. Así, la función informativa posibilita perspectivismos diversos, como el markeingarchivístico o las aplicaciones de las tecnologías de la información. Ello deviene en renovación de hábitos y reforma de prácticas archivísticas. ${ }^{44}$ En este orden de cosas, el despliegue de los dispares niveles de habilidad en el campo delos documentos electrónicos ${ }^{45}$ y sugestión es cada vez más prioritario.

41 Cfr. Fernández Benavide, C. "Nuevos retos, nuevas tecnologías", en IV JomadassdorelasTemdoǵas dela Infomación para la Modemizacoón delas Administracones Públicas Palma de Mallorca, 1995, pp. 10-12.

- López Crespo, Francisco: “Incorporación de las Nuevas Tecnologías a las Administraciones Públicas. Su incidencia en los Archivos", en TRÍA, 1996, n 3, pp. 99-103.

- Martínez Díaz, R. "Las tecnologías de la información en la mejora de la prestación de servicios al ciudadano y a las empresas”, en IJomadassdbelas TendoǵasdelaInformacón paralaModamizacónde las Administradiones Públicas Madrid, 1989, pp. 37-45.

42 Dollar, C.M. Theimpad of Infomation TehndogesonArchival PriniplesandPradiques SomeConsidara tions Washintong N.A.R.A., 1997.

43 Muñoz Cañavate, A. y Vivas Moreno, A. "Gestión de la información administrativa de las Administraciones Locales de Internet. Presencia institucional en la red”, en Revista españdadeDoumentaiónCientífica, 24, 2, pp.162-177.

44 Para el análisis de las nuevas funciones de la práctica archivística en el s. XXI vid

- Bourque, J., Couture, C. y Faucher, N. “Le défi archivistique à l'aube de l'an 2000", en Ardives 1997-98, vol. 29, 2, pp. 3-29.

- Lopes, L.C. "Vers une archivistique internationale à l'ere de l'information", en Ardhives 1997-98, vol. 29, 2, pp. 45-64.

- Lubar, Steven "Information Culture and Archival Record", en TheAmericanArdhivist, 1999, vol. 62, pp. 10-22.

- Millar, Laura “The spirit of Total Archives: seeking a Sustainable Archival System”, en Ardivania1999, vol. 47, pp. 45-65.

- Montersen, Preben “The place of Theory in Archival Practique”, en Ardivania 1999, vol. 47, pp. $2-26$.

-Zelenyj, Dan “Arcgivy ad portas: The Archives-Records Managemen Paradigm Re-visited in the Electronic Information Age”, en Arhivania. 1999, vol. 47, pp. 66-84.

45 Hacemos nuestra la definición que ofrece $\mathrm{M}^{\mathrm{a}} \mathrm{C}$. Marcos de documento electrónico: "unidades estructuras de información registrada, publicada o no publicada, y gestionadas como unidades discretas en sistemas de información". Evidentemente no todos los documentos electrónicos son documentos de archivo, dado que las características que debe reunir un documento para ser considerado parte del archivo no varían al cambiar de formato: "Un documento electrónico se convierte en documento de archivo cuando toma parte en una transacción de la organización" (Norma Autraliana AS 4390 Records Management. Parte 3, Apdo. 8.4.2). (Cfr. Marcos, M C. "Los Archivos en la era digital”, en El profesional delainfomaión vol. 8, nº 6, junio de 1999, pp. 4-8). 


\section{Inestigacoón Biblidteclógica v. 18 No. 36 enero/ junio de 2004}

Todo ello implica que se produzcan fuertes alteradionesen el procedimiento y en las técnicas. La multiplicación exponencial del volumen de información transferida y del número de consultas informatizadas que se producen en los centros, las primordiales vinculaciones funcionales entre el profesional de la gestión documental y el administrador del sistema informático -hasta tal punto que alguien los puede confundir-, las novedosas herramientas para la gestión de los documentos electrónicos en los noveles servicios de información y documentación, o la simple disminución del contacto entre el archivero ylos usuarios implica cambios cualitativos. ${ }^{46}$

En consecuencia, no cabe duda de que la gestión electrónica de documentos trae consigo numerosas e importantes ventajas en la resolución de problemas clásicos originados por el crecimiento continuo de documentación en las administraciones o el inevitable trasiego de numerosos documentos originales. $\mathrm{Al}$ mismo tiempo, ha permitido la trasferencia rápida de la información hacia puntos lejanos unificando el expediente por encima de los límites de las diferentes instituciones, e incluso poniendo a disposición de la investigación y la planificación una valiosa información en forma fácilmente tratable y accesible. Sin embargo, sin que esto suponga que pongamos más énfasis en los problemas que en las soluciones, elementos, que a mi entender son fundamentales por su originalidad en la disciplina, pueden quedar desubicados si no quedan perfilados más esclarecidamente. Es el caso, a pesar de los últimos avances normativos de la autenticadónylapreavacónde la información, ${ }^{47}$ donde la naturaleza jurídica del documento es uno de los asuntos prioritarios en la práctica archivística.

En definitiva, con esta nueva perspectiva de la función informativa, la archivística, y con ella su historia, pretende gestionar la información administrativa desde un enfoque integrador del sistema, y lo quiere hacer de forma eficaz que le permita enfrentarse a una sociedad que cambia vertiginosamente.

\section{CONCLUSIONES}

A riesgo de pretender simplificar algo que por su naturaleza se nos presenta como indeterminado, como es la configuración científico-técnica de la archivística como disciplina, máxime cuando, como hemos podido comprobar, los análisis más someros nos conducen hacia un complejo entramado de interacciones sociales y culturales, ofrecemos, derivado de los elementos de extraordinaria magnitud que articulan la configuración de la historia de la archivística, las siguientes conclusiones:

46 - Philps, J.T. "Metadata-Information about Electronic Records", en ARMA. 1995, 29, 4,pp. 52-73. - Dollar, C.M. TheimpadtofInfomationTehndogesanArdival PrindplesandPradiques SameConsidera tionsWashintong N.A.R.A., 1997.

- Cruz Mundet, J.R. “Los Archivos Administrativos: un reto para la profesión”, en TRIA. 1996, 3, pp. 15-34.

47 Cfr. Davara Rodríguez, M.A. "Validez y eficacia jurídica de los documentos electrónicos, informáticos y telemáticas", en IV JomadassdbreTemdoǵasdelaInformadónparala ModemizacóndelasAdmnistraiones Públicas TECNIMAP'95. Madrid: Ministerio de las Administraciones Públicas, 1995, pp. 135-172. 
$1^{a}$ La historia de la archivística se ha visto rodeada de determinados factores que han contribuido de forma decidida al desarrollo de la disciplina:

* la sustitución de la memoria y la palabra por la escritura como elemento transmisor y verificador de los contenidos culturales;

* las influencias de la práctica eclesiástica tanto en las pretensiones e intemporalidad del documento eclesiástico, los formalismos y usos de carácter sacro, o en la propia cohesión y complejidad de la administración eclesiástica;

* la salvaguarda jurídica de los derechos de particulares e instituciones mediante la interrelación de tres elementos: el derecho romano, la diplomática como disciplina científica y el notariado;

* la instrumentalización política ligada a la complejidad de las diferentes formas políticas, y la burocracia como requisito para convertir al archivo en un instrumento de privilegio y poder;

* la memoria histórica, vinculada a la concepción cientificista de la historia, y la consideración de ésta como instrumento de carácter cultural y político, para lo cual el documento de archivo se comporta como un instrumento verificador del discurso histórico;

* y, por último, la función informativa, ligada a la percepción integradora de la archivística, la formación armonizada con el resto de las profesiones de la información y la constatación del impacto de las tecnologías de la información.

$2^{a}$ Los factores socio-culturales expuestos representan las bases para confeccionar una histaiadelaarchivística delargaduradón esto es, el componente histórico racional-no lineal-de la disciplina. En otros términos, la HistaiaCultural delaArchivís tica se encuentra vinculada de forma directa a los factores analizados.

$3^{a}$ La archivística, en su devenir hacia una ciencia propia, se ha visto conectada de forma interdisciplinar con otras disciplinas. La antropología, la etnografía, la historia del derecho y de las instituciones, la paleografía y la diplomática, la historia, o la documentación son algunas de las ciencias que han ocasionado de forma directa la contextualización cultural de la archivística. Sin ellas, la historia de la archivística se torna incomprensible.

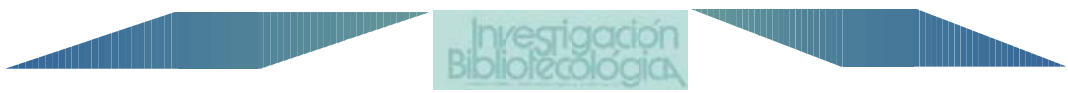

